\title{
THE NEXT 11: EMERGING INVESTMENT MARKET
}

\author{
Bader Riyad ALOnaizi a ${ }^{\text {, Prof. Yousr Gadhoum }}{ }^{\mathrm{b}}$ \\ a Saudi kayan an Affiliate of SABIC, Saudi Arabia \\ b Prince Mohammad Bin Fahd University, KSA \\ Corresponding email: onaizibr@saudikayan.sabic.com
}

\begin{abstract}
The next tier of emerging economies are those countries following the BRIC path which share the characteristics of typically high rates of population growth, creating a growing pool of potential consumers, at the same time as rising disposable incomes. In December 2005, another grouping was introduced called The Next 11 or $(\mathrm{N}-11)$ is a list of fast-growing countries identified by Goldman Sachs as potentially good investments in the coming years. The purpose was to identify those countries that could potentially have a BRIC-like impact in rivaling the $\mathrm{G} 7$. The result was a very diverse grouping that includes countries such as Bangladesh, Egypt, Indonesia, Iran, Korea, Mexico, Nigeria, Pakistan, Philippines, Turkey and Vietnam. Goldman Sachs based its selection on criteria such as macroeconomic stability, political maturity, openness of trade and investment policies, and the quality of education. The $\mathrm{N}-11$ is a diverse group on many levels such as broad representation, huge variation in development levels, levels of urbanization, population size and market development and investor focus. The $\mathrm{N}-11$ countries have significant growth potential, but still there are factors that could hamper them from following the BRIC growth path. First, the shifts in global commodity prices will affect the $\mathrm{N}-11$ producers of these commodities and domestic political events may also restrict growth prospects. Although, the $\mathrm{N}-11$ is implausible to rival the BRICs as a grouping in scale, N-11 GDP could reach two-thirds the size of the G7 by 2050.
\end{abstract}

Keywords: Invest Market, Emerging Economies \& Foreign Direct Investment.

\section{Introduction}

The Next Eleven (or N-11) refers to the eleven countries namely Bangladesh, Egypt, Indonesia, Iran, Mexico, Nigeria, Pakistan, the Philippines, South Korea, Turkey, and Vietnam that were identified by Goldman Sachs investment bank as having a high potential of becoming the world's largest economies in the 21st century. The bank chose these countries with promising outlooks for investment and future growth on December 12, 2005. Based on Goldman Sachs' criteria such as macroeconomic stability, political maturity, openness of trade and investment policies, and the quality of education. Although the 11 countries varied geographically and economically, they have common features that are believed to single out as their high economic potential. All have large and growing populations. Between 1980 to 2008, population growth was highest in Pakistan at the rate of 110.8\%, with South Korea as the lowest being, with $28.4 \%$ period growth. Among the N-11 countries, Indonesia had the largest population as of January 2008, with 228.9 million people, while South Korea had the smallest at 47.6 million people. In 2006, Mexico had the highest sum of private final consumption expenditure, with a total of US\$567 billion. Vietnam had US $\$ 36.8$ billion as the lowest. All of the 11 countries demonstrate population growth rates above those of Western developed economies which indicate a greater consumer market potential over the medium term. Large populations represent a wide potential pool of consumers for businesses to market, while high growth rates mean that this market will expand rapidly, providing more potential customers proportionally. 


\section{Asia Pacific Journal of Advanced Business and Social Studies \\ ISBN (eBook): 9780994365675 | ISSN : 2205-6033 \\ Year: 2017, Volume: 3, Issue: 2}

\section{The Purpose of the Study}

As a Saudi business student and future businessman, my main objective is to gather and equip myself with knowledge about the real world outside the four walls of our university. Competition in business is becoming very tough and it is the best weapon I can get while in school.

My topic does not only interest students but every citizen of any country for this is about the projected future of the world economy in general. People are increasingly becoming curious about the groupings made by Goldman Sachs, an investment bank, about the emerged and future emerging economies in the world. This new grouping does not only interest me but all citizens in every country because it concerns them as well. This motivates me to seek information and research for myself why this grouping made a popular following. As I do this research, I can educate myself about the subject, a topic that I should know and find some answers to those questions that been raised by in my mind. Considering that though, not all materials available on the internet and other sources are presenting the reliable information so we need to be open-minded to check for the veracity of the postings. We must have a good judgment before accepting what is being presented. Also, through this research I may able to share my humble knowledge base to my fellow students who I believe are also interested about the issue and create awareness that even as students, we need to start getting involve to the affairs of the world. Other skills may also develop like my proficiency in the English language. This research can improve my reading, writing, and comprehension in English. That at the end, I intend to know the effects of the Next 11, to their own respective countries and to the world economy. These are the questions that I intent to answer as I do this research paper.

1. What are the groupings $\mathrm{G} 7, \mathrm{BRIC}$ and $\mathrm{N}-11$ ?

2. What countries belong to each group?

3. Which grouping does Saudi Arabia and other GCC countries belong?

4. What are the prospects for the $\mathrm{N}-11$ over the next decades?

5. Can the $\mathrm{N}-11$ dream become reality?

6. What are the obstacles to success?

7. What are the effects of $\mathrm{N}-11$ to world economy?

\section{Research Feasibility}

With the given proper instructions and guidance from our professor, enough time to prepare, availability of research materials, and strong motivation to do a very interesting and timely topic about the Next 11 emerging countries, I believe that can finish this research paper and can submit it on time. Source information is not too difficult to find because of several reasons working in my advantage such as availability of diversified information from the universe of information that the internet can provide, periodical like newspaper, magazines and books. Second reason is because the topic that I have chosen interests a lot of people from all walks of life, particularly students, governments, financial analyst, economist and scholars which have different views about the topic. And lastly, this knowledge has been there for 5 years, though it's not that long and still serve as new information for some, a lot of factual facts have been circulating and documented by respectable institution in the field. So the availability of source information is not a burden on my part.

\section{Methodology}

Research designs are plans and the procedures for research that span the decisions from broad assumptions to detailed methods of data collection and analysis (Cresewell, 2009). The research design approach I am planning to execute for this project on the Next Eleven $(\mathrm{N}-11)$ is a Mixed research which is a typical type of research approach in which quantitative and qualitative methods, techniques, or other paradigm characteristics are mixed in the 
overall study. Mixed Research which combines both qualitative and quantitative techniques. Qualitative in the sense that, it involves emerging questions and procedures, data analysis and quantitative techniques in the sense that, it will involve analyzing numbered data. Mixed model research specifically, is research design in which the researcher mixes both qualitative and quantitative research approaches within a phase of the study or across two of the phases or stages of the research process. For example, I might collect qualitative data but then try to quantify the data or I might conduct a survey and use a questionnaire that is composed of multiple closed-ended or quantitative type items, in addition to several open-ended or qualitative type items.

\section{Definition of Terms}

1. The Next Eleven (or N-11) are eleven countries-Bangladesh, Egypt, Indonesia, Iran, Mexico, Nigeria, Pakistan, Philippines, South Korea, Turkey, and Vietnamidentified by Goldman Sachs investment bank as having a high potential of becoming the world's largest economies in the 21st century along with the BRICs. The bank chose these states, all with promising outlooks for investment and future growth, on December 12, 2005 (Wikipedia Foundation Inc, 2010).

2. The G7 (also known as the G-7) is the meeting of the finance ministers from a group of seven industrialized nations. It was formed in 1976, when Canada joined the Group of Six: France, Germany, Italy, Japan, United Kingdom, and United States. (Britannica online, 2008)

3. In economics, BRIC (typically rendered as "the BRICs" or "the BRIC countries" or known as the "Big Four") is a grouping acronym that refers to the countries of Brazil, Russia, India, and China that are deemed to all be at a similar stage of newly advanced economic development (Wikipedia Foundation Inc, 2010).

4. Growth Environment Scores (GES) - represents a composite measure of growth conditions for 170 countries, aimed at summarizing the overall growth environment. Goldman Sachs introduces the GES in 2005, to rank countries according to their ability to achieve their growth potential (Sach, 2007).

5. OECD (Organization for Economic Co-operation and Development) is an international economic organization of 34 countries founded in 1961 to stimulate economic progress and world trade. It defines itself as a forum of countries committed to democracy and the market economy, providing a platform to compare policy experiences, seeking answers to common problems, identifying good practices, and cocoordinating domestic and international policies of its members (Wikipedia Foundation Inc, 2010).

6. Foreign direct investment (FDI) or foreign investment refers to long term participation by country A into country B. It usually involves participation in management, joint-venture, transfer of technology and expertise. There are two types of FDI: inward foreign direct investment and outward foreign direct investment, resulting in a net FDI inflow (positive or negative) and "stock of foreign direct investment", which is the cumulative number for a given period. Direct investment excludes investment through purchase of shares (Wikipedia Foundation Inc, 2010).

\section{Literature Review}

Background

Everyone must know by now what "The G7" (G-7) means. The group of seven (7) industrialized countries in the world which composed of Canada, France, Germany, Italy, Japan, the United Kingdom and the United States of America (USA). It was formed in 1976 as an economic and political group of the seven largest developed and powerful groups of 


\section{Asia Pacific Journal of Advanced Business and Social Studies \\ ISBN (eBook): 9780994365675 | ISSN : 2205-6033 \\ Year: 2017 , Volume: 3, Issue: 2}

nations which does not include any developing nations. Another grouping was introduced by a company named Goldman Sachs Group Inc., which was founded in 1869. It is a global investment banking and securities firm which engages in investment banking, securities, investment management, and other financial services primarily with institutional clients. In 2003, Goldman Sachs introduced the grouping called "BRIC" countries also known as "Big Four", an acronym coined to describe four top emerging markets composed of Brazil, Russia, India, and China. The BRIC countries have gained a widespread use as a symbol of the shift in global economic power away from the developed G7 economies toward the developing world. These countries have a gigantic part of the world's economy and natural resources. And all together, they account for around 25 percent of the global land mass and 40 percent of the world's population.

Late part of 2005, another grouping was introduced called "The Next 11"or (N-11). It is a list of fast-growing countries identified by Goldman Sachs as potentially good investments in the coming years. The purpose was to identify those countries that could potentially have a BRIC-like impact in rivaling the G7. These 11 countries have main common ground and the reason for their selection was that they were the next set of large-population countries beyond the BRICs. The result was a very diverse grouping that includes countries such as Bangladesh, Egypt, Indonesia, Iran, Korea, Mexico, Nigeria, Pakistan, Philippines, Turkey and Vietnam. Population and potential size are the key common features among the group. Aside from those things in common, these countries are a diverse group on many dimensions, including regional representation, population size, level of economic and market development, and integration with the global economy. Goldman Sachs based its selection on criteria such as macroeconomic stability, political maturity, openness of trade and investment policies, and the quality of education. Accordingly, the Next Eleven (or N-11) is the eleven countries having a high potential of becoming the world's largest economies in the 21st century.

\subsection{The Goldman Sach's Selection}

The 2003 Goldman Sachs' original research focused on economies of Brazil, Russia, India and China. Goldman Sachs introduce the grouping called "BRIC" countries also known as Four", an acronym coined to describe the four top emerging markets with the greatest development potential to 2050 on basis of positive economic fundamentals, large and growing populations, and the ability to exploit resource assets. By 2008

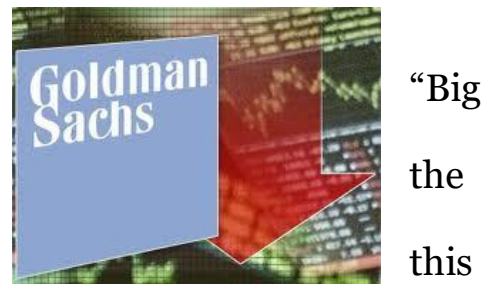
hypothesis is playing out. All the BRIC countries have posted consistent economic growth since 2001, despite the global economic downturn of 2001-2002.

Late 2005, Goldman Sachs introduced another grouping called "the Next Eleven" or (N-11). The purpose was to identify those countries that could potentially have a BRIC-like impact in rivaling the G7. Their main common ground and the reason for their selection was that they were the next set of large-population countries beyond the BRICs. The result was a very diverse grouping that includes Bangladesh, Egypt, Indonesia, Iran, Korea, Mexico, Nigeria, Pakistan, Philippines, Turkey and Vietnam. Some economies that are well-known to many investors are countries such as Korea and Mexico but also many that are not are Nigeria, Vietnam, Pakistan and Bangladesh.

\subsection{G-7, BRIC, and N-11 Countries}

Goldman Sach took a similar approach to BRICs analysis back in 2003, looking into details of some simple assumptions for the growth process entail for the $\mathrm{N}-11$ economies, and benchmarks these against the BRICs and the G7. Growth conditions was also compared using the Growth Environment Scores (GES) which highlights the strengths and 


\section{Asia Pacific Journal of Advanced Business and Social Studies \\ ISBN (eBook): 9780994365675 | ISSN : 2205-6033 \\ Year: 2017 , Volume: 3, Issue: 2}

weaknesses across the group (Wilson \& Stupnytska, 2007).. The diversity of the N-11 economies make it difficult to generalize but the projections confirm that many of them have interesting growth potential characteristics, alongside a reasonable scale, although their prospects may vary widely and some may face much greater challenges than the others. There is no doubt though that the BRICs remain by far the bigger global story. But while each of the $\mathrm{N}-11$ may not have a BRIC-like impact soon, the $\mathrm{N}-11$ as a group may have the capacity to rival the $\mathrm{G} 7$, if not in absolute terms, then at least in terms of new growth. And many of them could still deliver the kind of sustained growth stories in extensive markets that will be increasingly hard to find in the developed world.

Of the N-11, only Mexico, Korea and, to a lesser degree, Turkey and Vietnam have both the potential and the conditions to rival the current major economies or the BRICs countries. Other $\mathrm{N}-11$ economies particularly Indonesia and Nigeria have the scale to be important if they can sustain growth.

For some of the $\mathrm{N}-11$, benchmark growth conditions are even higher. This uncertainty and the fact that some of these economies lay well off traditional radar screens makes parts of the $\mathrm{N}-11$ so intriguing. If some of these economies can defy skeptics and take concrete forward steps towards addressing areas of weakness, their growth could be much bigger. While the grouping may seem less coherent than the BRICs, this potential and probably the diversification offered by their many differences makes them an interesting group from an investment point of view. The Growth Environment Scores (GES) suggest that concrete progress so far is uneven and modest, although several N-11 members have made their desire to move down this path clearer in the past years. They may not succeed, but they do merit closer attention as a result. "In gauging the chances of success, we are conscious that the recent global picture high commodity prices, low real interest rates, solid global growth and low market volatility has been unusually favorable for emerging markets" (Wilson \& Stupnytska, 2007). Until the environment is tested, it will be hard to determine whether the recent optimism about some of these economies represents a fundamental change or just a repeated boom. For the N-11 countries, improving growth conditions during the benign global backdrop is more likely to offer the best chance of weathering the next storm whenever it comes.

\subsection{N11 business environments}

Business environment is a major contributing factor for potential growth. Investors definitely will choose to invest in country where operating environments are not too difficult, permits potential wage and job growth.

The N11 countries vary in their business environments which affects their relative attractiveness as an investment destination. Like, South Korea was ranked 3oth from 178 countries in the World Bank's 2007 Ease of Doing Business survey, the highest among the N11 countries. Attributed to its well-regulated tax and investment code which is influenced by the US model, and the adherence of state and financial institutions to its code. While, Iran ranked the lowest at $135^{\text {th }}$ place, reflects its authoritarian state-owned business environment where in many cases actively discourage foreign investors. In other cases, the regulatory environment is unclear and subjective, offering few incentives for new investment.

In 2006, Turkey received US $\$ 20.1$ billion new investment, the greatest amount of foreign direct investment among the N11 countries. Probably because of its strategic geographic location as the bridge between Europe and the Middle East, and its consequent position as an export and re-export hub. In contrast, Iran received the least foreign direct investment of US\$901 million, indicating its investor unfriendly business environment and also the economic sanctions imposed on them by the US government. 


\begin{tabular}{|c|c|c|c|c|c|c|c|c|c|}
\hline \multicolumn{10}{|c|}{ Characteristics Diversity } \\
\hline & 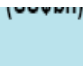 & $(\%)$ & 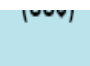 & & 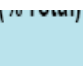 & GDP $)^{*}$ & ו & ( $\%$ GDP) & 100 \\
\hline ladesh & 63 & 5.7 & 427 & 155 & 25.0 & 36.7 & 1.1 & -0.3 & $\overline{6.8}$ \\
\hline il & 1,064 & 2.3 & 5,085 & 187 & 84.2 & 22.7 & 1.7 & 1.4 & 4.2 \\
\hline a & 2,682 & 9.8 & 2,041 & 1,314 & 40.5 & 63.4 & 3.2 & 8.6 & 1.5 \\
\hline \multirow[t]{2}{*}{ it } & 101 & 4.2 & 1,281 & 72 & 42.3 & 56.8 & 6.4 & 1.8 & 7.3 \\
\hline & 909 & 7.2 & 696 & 1,110 & 28.7 & 29.3 & 0.8 & -2.4 & 5.6 \\
\hline \multirow[t]{2}{*}{ Iesia } & 350 & 4.8 & 1,510 & 222 & 47.9 & 51.2 & 1.9 & 2.4 & 13.1 \\
\hline & 245 & 5.7 & 3,768 & 71 & 68.1 & 51.5 & 0.0 & 10.0 & $14 . \mathrm{C}$ \\
\hline a & 887 & 4.5 & 18,484 & 49 & 80.8 & 68.5 & 0.9 & 0.7 & 2.2 \\
\hline co & 851 & 2.3 & 7,915 & 107 & 76.0 & 57.4 & 2.3 & -0.4 & 3.6 \\
\hline ria & 121 & 5.6 & 919 & 150 & 48.3 & 71.9 & 3.4 & 15.7 & 9.4 \\
\hline stan & 129 & 5.3 & 778 & 155 & 34.8 & 35.5 & 2.0 & -3.9 & 7.9 \\
\hline spines & 117 & 5.0 & 1,314 & 86 & 62.6 & 90.7 & 1.2 & 3.1 & 6.3 \\
\hline ila & 982 & 6.2 & 6,908 & 142 & 73.3 & 44.2 & 1.9 & 10.3 & 9.9 \\
\hline әу & 390 & 4.6 & 5,551 & 73 & 67.3 & 51.8 & 2.7 & -8.0 & 10.2 \\
\hline Iam & 55 & 7.6 & 655 & 84 & 26.7 & 132.2 & 3.9 & 0.1 & 7.6 \\
\hline
\end{tabular}

The $\mathrm{N}-11$ is a diverse group on many levels. First, Broad representation, across major continents, with one economy from each region like in Europe, Latin America and the Middle East. One from Latin America, two from Africa, two from the Sub-Continent, and four from East and South-East Asia.

$$
\text { ie BRICs, N-11 and the World }
$$

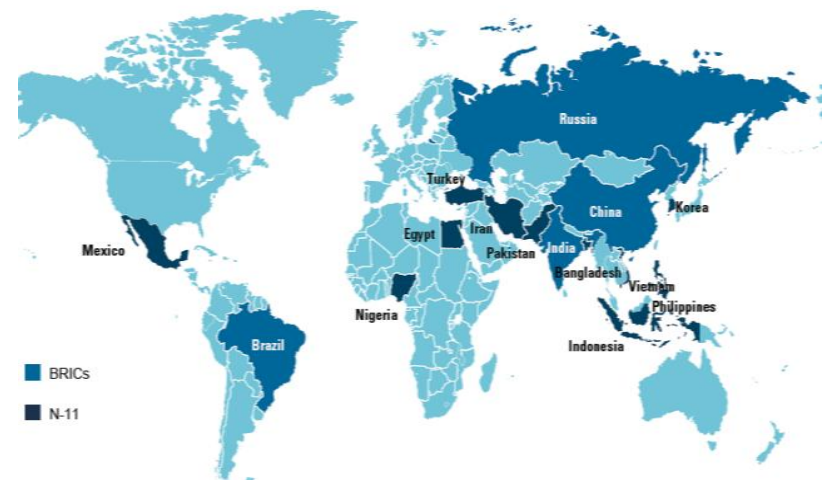

Second, Huge variation in development levels. Like Korea, classified as an emerging market in financial terms, is in most respects a developed economy, with income levels more than twice as high as any of the $\mathrm{N}-11$ countries. Mexico, the next richest, which is already an OECD member. Turkey also is quite well-off by developing standards. In contrast, Bangladesh is one of the world's poorest countries.

Third, Levels of urbanization, openness to trade and the role of FDI in the economy also vary significantly, with the less developed economies showing a strong rural bias and direct foreign involvement in the economy ranging from non-existent such as Iran to significant in the likes of Nigeria and Vietnam. But trade shares are generally quite high at $60 \%$ of GDP in 2005. Four economies boast higher trade shares than China the most open among BRIC.

Fourth, Population size is also relatively different across the group. While all of the $\mathrm{N}-11$ are by design relatively large, but none rivals China or India, populations vary from around 50 million Koreans to well populous 200 million Indonesians. 


\section{Asia Pacific Journal of Advanced Business and Social Studies

Lastly, Market development and investor focus differ also. While five of the N-11 namely Turkey, Korea, Indonesia, Philippines and Mexico, are commonly found in Emerging Market investment indices, the other six generally attract much less interest. Also, the ability to access the markets varies widely.

\section{4 Impending Downside}

Though, the N11 countries have significant growth potential, still there are factors that could hamper them from following the BRIC growth path.

First, the shifts in global commodity prices will affect the N11 producers of these commodities. For instance, all except South Korea are oil producers. Although, Mexico and Iran are the only consistent net oil exporters. Accordingly, high oil prices will benefit Mexico and Iran in particular, although the other producers will benefit as well, since their domestic supply will limit the amount of imported oil required, and hence a higher import cost.

Second, domestic political events may also restrict growth prospects. Like the ongoing political unsteadiness in Pakistan and Bangladesh may deter investment, also the terrorist activities if insurgent groups in Indonesia, the Philippines, Nigeria and Turkey could also act as a disincentive for growth.

The global market moves particularly of export commodities, and the domestic political situation could act to counteract the investment incentives offered to these countries. This could limit the potential for economic growth, with likewise negative implications for consumer spending growth.

\subsection{Changes to Realize N-11 Dream}

Within the N-11 group, Vietnam is the closest to Best in Class levels of the GES while the furthest away is Nigeria. While many $\mathrm{N}-11$ governments appear to be more focused on enhancing growth conditions, hard measures such as the GES have not yet captured significant broad progress, except in Turkey and Iran to a lesser extent. Since our projections account to some extent for current growth conditions, significant progress in improving growth conditions could lead to substantial growth bonuses in some places beyond these projections. This bonus could be as much as 3\% to $4 \%$ in Bangladesh, Nigeria and Pakistan (Wilson \& Stupnytska, 2007).

These changes would be enough to change the path of the projections in dramatic rate. With a significant improvement to growth conditions, for example in Nigeria and Indonesia would possibly rival the smaller of the BRICs over time.

\subsection{Prospective Scenarios}

Both domestic and international factors will affect the growth prospects for the $\mathrm{N}-11$ countries. Demand from key export markets will determine economic growth. Countries such as the United States of America and China are the main export markets for the $\mathrm{N}-11$ countries. Although US GDP growth is forecast to reach only $1.9 \%$ year-on-year in 2008 owing to ongoing concerns about poor credit, on the other hand China's economy will grow by $10 \%$ (Eghbal, 2008).

Those countries that are most stable whether democracy or dictatorship form of government will have better prospects for consistent growth. These include nations such as South Korea, Vietnam, Mexico and Egypt. Theey factor for Iran will be the continuation of economic sanctions by the US government, which would curtail Iran's economy growth. 


\section{Future Growth Prospect}
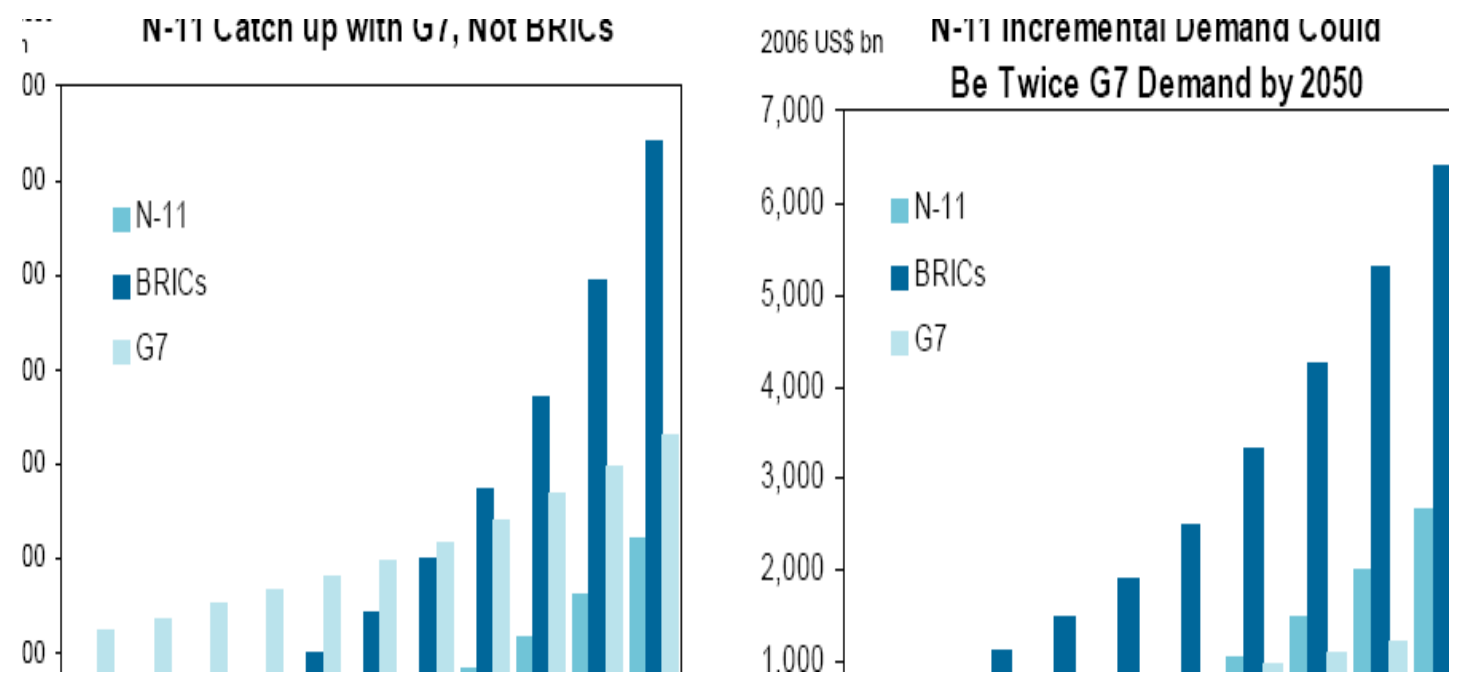

The N-11 is unlikely to rival the BRICs as a grouping in scale, Although, N-11 GDP could reach two-thirds the size of the $\mathrm{G} 7$ by 2050 . All of the $\mathrm{N}-11$ has the capacity to grow $4 \%$ or even more over the next 20 years, if they can maintain stable conditions for growth. Incremental new demand from the $\mathrm{N}-11$ could conceivably overtake the $\mathrm{G} 7$ in about 25 years and be two times that of the $\mathrm{G} 7$ by 2050, therefore, their growth contribution will rise faster. Of the N-11, only Mexico and Indonesia have the potential to rival all but the largest of the G7, but Nigeria, Korea, Turkey and Vietnam might all overtake some of the current G7 economies (Sach, 2007).

Even with solid growth, only Korea and Mexico and Turkey perhaps are likely to have a reasonable chance of catching up to developed country income levels over the next few decades. And the ranking of income levels is less likely to change than the ranking of economy size. Other $\mathrm{N}-11$ countries could still see large rises in incomes especially Vietnam with potentially the most spectacular, of a possibly more than fivefold increase in the next 25 years (Wilson \& Stupnytska, 2007).

The current shifts towards developing economies and towards Asia, which is currently driven by the BRICs, are most likely to be reinforced if the N-11 dream becomes reality.

\section{Conclusion}

The focus of interest is now on the $\mathrm{N}-11$ since its recognition as a group of potentially large, fast-growing markets, with rising incomes and activity, which could be an important source of growth and opportunity for nations, companies and investors both in the international and local arena over the next two decades. If the $\mathrm{N}-11$ can begin to deliver on some of their increasingly stated desires to improve growth conditions though the challenge before many of them is still very large, they may end up proving to be among the most interesting investment stories of the next decade or more.

Ironically, it is the evident doubtfulness of some of these stories that helps to make the $\mathrm{N}-11$ an exciting story to reckon. When Goldman Sach produced its original BRICs projections, a few years ago, it was clearly remembered the widespread skepticism for the importance of all of the BRICs except China. It is hard now to believe that Indian growth story was challenged 
so strongly. "But we have also seen greater recognition of the domestic growth and investment opportunities in the other BRICs too, alongside plenty of pushback! And the recent performance of many of the $\mathrm{N}-11$ is already better than many expected, or perhaps realize" (Sach, 2007).

The focus here is not to pick winners or pin down the loser if the projected growth is not attained but rather to provide a road-map for assessing the kind of growth that each of the $\mathrm{N}-11$ could deliver and the problems that need to be addressed to get there. Also, the goal here is fleshing out the $\mathrm{N}-11$ dream, not to predict the future but rather to explore the frontiers of what might be possibly accomplished. In the process, it is hoped to improve the understanding of some of the big changes in the world economy that may lie ahead. I'm sure you have more of them by now but here are our curious questions. Could Mexico be a strong contender to the BRICs? Could Turkey become the second largest economy in the European continent? Could Vietnam make it to join the ranks of the major economies? Could Nigeria outperform Italy? And what would need to happen for the realization of these developments? The fact that these questions are asked is itself a testimony to the shifts in the global economy that are already in progress.

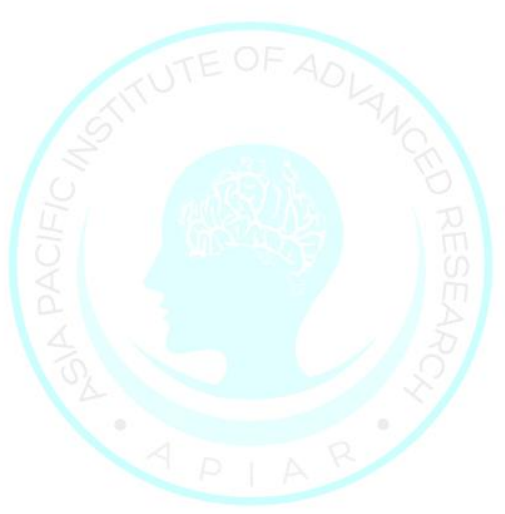




\section{References}

i. $\quad$ Eghbal, M., 2008. The Next 11 emerging economies. Euromonitor International 2010. [Online] Available at: http://www.euromonitor.com_[Accessed 22 December 2010].

ii. $\quad$ Rowland, R., 2010. The Market Oracle. Emerging Market Investing 2010 in the Next 11 after BRIC. Stock-Markets / Investing 2010. [Online] Available at: http://www.MarketOracle.co.uk_[Accessed 22 December 2010].

iii. Sach, G., 2007. Global Economic Paper no. 153. Economic Research Issue no. 153. [Online] Available at: https://portal.gs.com [Accessed 22 December 2010].

iv. Wikipedia Foundation Inc, 2010. Next Eleven. [Online] Available at: http://en.wikipedia.org_[Accessed 22 December 2010].

v. Wilson, D. \& Stupnytska, A., 2007. The N-11: More than an acronym. [Online] Available at: http://www.marketoracle.co.uk/_[Accessed 22 December 2010]. 